\title{
Linking Evidence Reviews to Organizational Guideline Planning: A Pilot Test of an Interactive, Web-Based Presentation and Discussion of Evidence
}

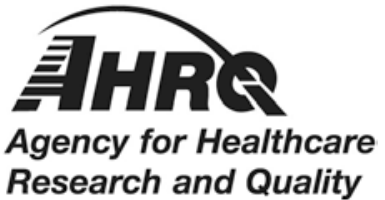




\section{Linking Evidence Reviews to Organizational Guideline Planning: A Pilot Test of an Interactive, Web-Based Presentation and Discussion of Evidence}

Prepared for:

Agency for Healthcare Research and Quality

U.S. Department of Health and Human Services

5600 Fishers Lane

Rockville, MD 20857

www.ahrq.gov

Contract No. 290-2015-00007-I, 290-2015-00010-I

Prepared by:

Kaiser Permanente Research Affiliates Evidence-based Practice Center

Portland, OR

Southern California Evidence-based Practice Center-RAND Corporation

Santa Monica, CA

Investigators:

Jennifer S. Lin, M.D., M.C.R.

Lisa V. Rubenstein, M.D., M.S.P.H.

Tracy L. Beil, M.S.

Susanne Hempel, Ph.D.

AHRQ Publication No. 18(19)-EHC025-EF

October 2018 


\section{Key Messages}

\section{Purpose of review}

We pilot-tested the effectiveness of a cyberseminar (an interactive, web-based presentation and discussion of evidence) in integrating systematic review findings into organization-specific clinical guidelines within a large, integrated health system. This project was undertaken in collaboration with key partners at the Kaiser Permanente Care Management Institute. Our core learnings include:

\section{Key messages}

- Dynamic presentation formats can simultaneously address the evidence needs of highlevel health system decision-makers and those working to implement clinical guidelines.

- Timing and organizational readiness are critical to the adoption of evidence.

- There is a need for evidence to be placed into a larger decisional context for optimal use by health systems. 
This report is based on research conducted by the Kaiser Permanente Research Affiliates Evidence-based Practice Center (EPC) and the Southern California Evidence-based Practice Center-RAND Corporation under contract to the Agency for Healthcare Research and Quality (AHRQ), Rockville, MD (Contract No. HHSA 290-2015-00007-I, HHSA290-2015-00010-I). The findings and conclusions in this document are those of the authors, who are responsible for its contents; the findings and conclusions do not necessarily represent the views of AHRQ. Therefore, no statement in this report should be construed as an official position of AHRQ or of the U.S. Department of Health and Human Services.

\section{None of the investigators have any affiliations or financial involvement that conflicts with the material presented in this report.}

The information in this report is intended to help health care decisionmakers-patients and clinicians, health system leaders, and policymakers, among others-make well-informed decisions and thereby improve the quality of health care services. This report is not intended to be a substitute for the application of clinical judgment. Anyone who makes decisions concerning the provision of clinical care should consider this report in the same way as any medical reference and in conjunction with all other pertinent information, i.e., in the context of available resources and circumstances presented by individual patients.

This report is made available to the public under the terms of a licensing agreement between the author and the Agency for Healthcare Research and Quality. This report may be used and reprinted without permission except those copyrighted materials that are clearly noted in the report. Further reproduction of those copyrighted materials is prohibited without the express permission of copyright holders.

AHRQ or U.S. Department of Health and Human Services endorsement of any derivative products that may be developed from this report, such as clinical practice guidelines, other quality enhancement tools, or reimbursement or coverage policies may not be stated or implied.

Persons using assistive technology may not be able to fully access information in this report. For assistance contact EPC@ahrq.hhs.gov.

Suggested citation: Lin JS, Rubenstein LV, Beil TL, Hempel, S. Linking Evidence Reviews to Organizational Guideline Planning: A Pilot Test of an Interactive, Web-Based Presentation and Discussion of Evidence. Methods Research Report. (Prepared by the Kaiser Permanente Research Affiliates Evidence-based Practice Center under Contract No. 290-2015-00007-I and the Southern California Evidence-based Practice Center-RAND Corporation under Contract No. 290-2015-00010-I.) AHRQ Publication No. 18(19)-EHC025-EF. Rockville, MD: Agency for Healthcare Research and Quality. October 2018. Posted final reports are located on the Effective Health Care Program search page.

DOI: https://doi.org/10.23970/AHRQEPCMETHENGAGELINKING. 


\section{Preface}

The Agency for Healthcare Research and Quality (AHRQ), through its Evidence-based Practice Centers (EPCs), sponsors the development of evidence reports and technology assessments to assist public- and private-sector organizations in their efforts to improve the quality of health care in the United States.

The reports and assessments provide organizations with comprehensive, science-based information on common, costly medical conditions and new health care technologies and strategies. The EPCs systematically review the relevant scientific literature on topics assigned to them by AHRQ and conduct additional analyses when appropriate prior to developing their reports and assessments.

To improve the scientific rigor of these evidence reports, AHRQ supports empiric research by the EPCs to help understand or improve complex methodologic issues in systematic reviews. These methods research projects are intended to contribute to the research base in and be used to improve the science of systematic reviews. They are not intended to be guidance to the EPC program, although may be considered by EPCs along with other scientific research when determining EPC program methods guidance.

AHRQ expects that the EPC evidence reports and technology assessments will inform individual health plans, providers, and purchasers as well as the health care system as a whole by providing important information to help improve health care quality. The reports undergo peer review prior to their release as a final report.

If you have comments on this Methods Research Project they may be sent by mail to the Task Order Officer named below at: Agency for Healthcare Research and Quality, 5600 Fishers Lane, Rockville, MD 20857, or by email to epc@ahrq.hhs.gov.

Gopal Khanna, M.B.A.

Director

Agency for Healthcare Research and Quality

Stephanie Chang, M.D., M.P.H.

Director

Evidence-based Practice Center Program

Center for Evidence and Practice Improvement

Agency for Healthcare Research and Quality
Arlene Bierman, M.D., M.S.

Director

Center for Evidence and Practice

Improvement

Agency for Healthcare Research and Quality

Jasmine Bihm, Dr.P.H., M.P.H.

Task Order Officer

Center for Evidence and Practice

Improvement

Agency for Healthcare Research and Quality

Christine Chang, M.D., M.P.H.

Task Order Officer

Center for Evidence and Practice

Improvement

Agency for Healthcare Research and Quality 


\section{Acknowledgments}

The authors gratefully acknowledge the following individuals for their contributions to this project: our partners at Kaiser Permanente Care Management Institute Helen Wu, Ph.D., Craig Robbins, M.D., M.P.H., Elizabeth (Beth) Liles, M.D., M.C.R., and Qiana Amos, M.P.H., for work in developing, executing, and evaluating this pilot project; our project officers at AHRQ Jasmine Bihm, Dr.P.H., M.P.H., and Christine Chang, M.D., M.P.H., for their guidance during this pilot project; and Katherine Essick, B.S., Aneesa Motala, B.S., and Olamigoke Akinniranye, M.S., for editorial assistance. 


\section{Linking Evidence Reviews to Organizational Guideline Planning: A Pilot Test of an Interactive, Web-Based Presentation and Discussion of Evidence}

\section{Structured Abstract}

Objectives. The goal of the Clinical Operations Evidence Review cyberseminar pilot project was to develop and test a method for facilitating the adoption and implementation of an EPC report's findings into a health system's clinical guideline.

Methods. This project was a collaboration with key partners at the Kaiser Permanente Care Management Institute (CMI). Over several months, we developed, implemented, and evaluated a 1-hour interactive, web-based presentation and discussion of evidence on interventions to prevent (or delay) the onset of diabetes. Through phone interviews and an online survey, we evaluated the content and usefulness of the EPC report to inform a clinical operations guideline and implementation process, the utility of the cyberseminar itself, and the extent to which this process was likely to inform decision-making at Kaiser Permanente.

Results. The cyberseminar: (1) targeted multiple disciplines and levels of leadership in the decision-making process, (2) engaged participants using an interactive rather than didactic (static) format, and (3) delivered the evidence in a context relevant to stakeholders. Stakeholders included members of Kaiser Permanente's diabetes guideline development team and national and regional implementation leaders for diabetes prevention efforts within Kaiser Permanente.

The cyberseminar was well received and served the needs of the guideline development team. The presentation focused on a high-level summary of the systematic review evidence; comparison of review findings with other systematic reviews; a description of implementation issues for included lifestyle interventions; a review of CMS reimbursement for lifestyle interventions; and a discussion about pre-identified considerations. Our key partners at CMI agreed that hearing from people working on implementation of diabetes prevention interventions in different regions was helpful, as was being able to query evidence reviewers during and after the cyberseminar. Guideline developers reported that the cyberseminar would change aspects of guideline and process.

Participants identified several areas EPC reports could address beyond effectiveness and harms that would be particularly helpful to health care organizations, including: (1) information about implementation and monitoring considerations for included interventions, (2) information on important subgroups, (3) (if applicable) information on how reports have been used to inform national guidelines, and (4) consistency between report findings and other existing systematic reviews.

Conclusions. Our pilot cyberseminar shows promise as a dynamic format to link evidence and evidence reviewers to organization-specific guideline development, and to integrate key stakeholders into the early guideline development process. The success of this effort required both the readiness of the health system and a partnership between evidence reviewers and the health system. 


\section{Contents}

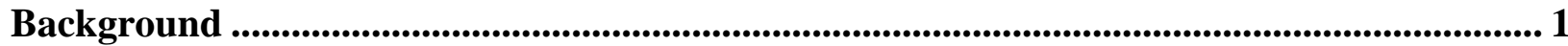

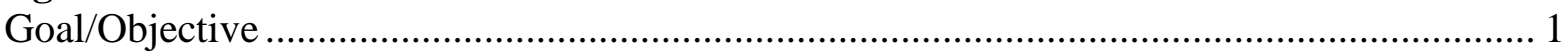

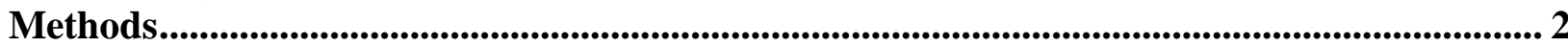

Health System and Representative Description .......................................................... 2

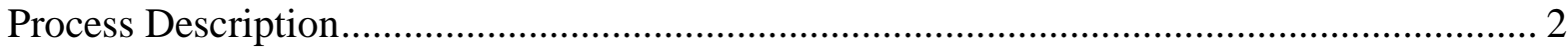

Evaluation Methods ..................................................................................................... 4

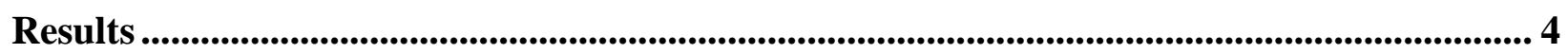

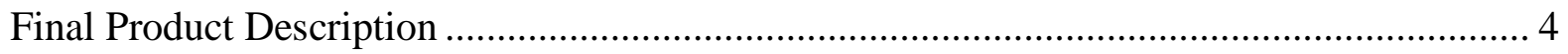

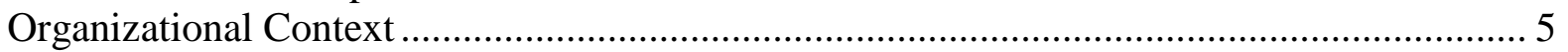

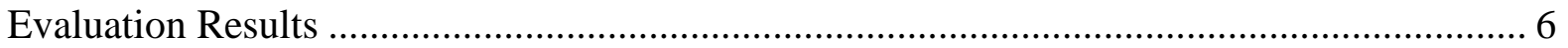

Evaluation of the Cyberseminar................................................................................. 6

Evaluation of the EPC Report................................................................................ 7

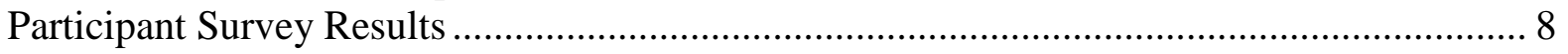

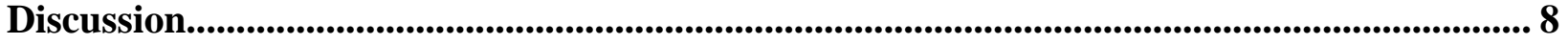

Value and Applicability to Other Health Systems ......................................................... 8

Lessons Learned and Applicability for Other EPC Reports ............................................ 10

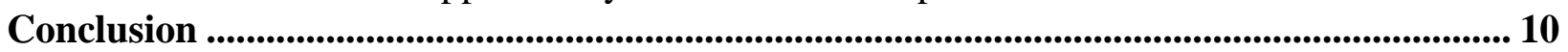

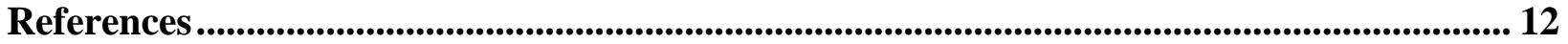

\section{Table}

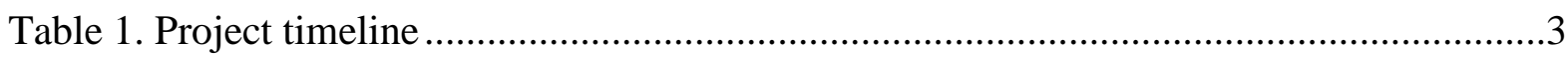

\section{Appendixes}

Appendix A. Interview Guide

Appendix B. Prediabetes Interactive Evidence Review Cyberseminar Survey

Appendix C. Cyberseminar Slides and Presentation Notes

Appendix D. Cyberseminar Pre-Seminar Questions 


\section{Background}

It may take many years for effective interventions to be widely implemented in health-care delivery organizations. While research syntheses continue to identify interventions with the potential to improve health care, dissemination of the findings is slow. Diffusion of innovation and adoption of promising research findings are complex. ${ }^{1}$ Research into methods that may help to close the gap between research and practice is critical to promote evidence-based practice in health care. Making evidence syntheses available to health-care delivery organizations alone may not be enough. Research and researchers are often criticized as being too distant from day-to-day health care practice, ${ }^{2-3}$ and practitioners emphasize that research findings do not provide useful guides to action. ${ }^{4}$ Approaches that facilitate thinking through what a particular piece of research might mean for practice in a specific setting and engaging practitioners may help to adopt systematic review findings in clinical practice.

Systematic evidence reviews produced by Evidence-based Practice Centers (EPCs) are used by groups, such as clinical professional organizations, health care organizations, and federal agencies, to inform clinical practice guideline development, program planning, and research priorities. The Agency for Healthcare Research and Quality's (AHRQ) EPC program wants to improve the utility and increase the uptake of existing EPC reports by health systems. To support this goal, AHRQ funded the EPCs to partner with health systems to develop and test dissemination and implementation products that would help health systems utilize EPC reports.

Health systems rely on systematic reviews and research-based evidence when creating, adopting, and adapting clinical guidelines as the basis of their policies and practices. These guidelines influence a range of decisions integral to the delivery of care within a system (e.g., decision-making regarding training, patient safety procedures, improvement targets, service delivery options), as well as system policy (e.g., patient eligibility, staffing requirements, mandated programs).

The Kaiser Permanente Research Affiliates (KPRA) and Southern California (RAND) EPCs worked together to develop and test an interactive seminar tool-the Clinical Operations Evidence Review (COER) cyberseminar-to facilitate the uptake of EPC report findings by Kaiser Permanente, a large, integrated health care system in eight states (California, Colorado Georgia, Hawaii, Maryland, Oregon, Virginia, Washington) and the District of Columbia. Kaiser Permanente has close to 12 million members and is the largest managed care organization in the United States.

The COER cyberseminar was conceptualized as a 1-hour interactive, web-based presentation and discussion by EPC and health system leaders responsible for guideline development. The cyberseminar's design was informed by the RAND EPC's expert panel work, the Veterans Administration (VA) cyberseminar program for national dissemination of research, and the KPRA EPC's experience working with the United States Preventive Services Task Force (USPSTF).

\section{Goal/Objective}

The primary goal of the COER cyberseminar project was to develop and test a method to facilitate the successful adoption and implementation of an EPC report's findings into a clinical guideline developed by a health system. In support of that goal, we brought together those who develop and implement clinical guidelines along with evidence reviewers to learn from each other's experiences. We also evaluated the development process and the COER cyberseminar to 
make actionable recommendations for AHRQ and the EPC program to support their goal of improving the utility and increasing the uptake of existing EPC reports by health systems.

\section{Methods}

\section{Health System and Representative Description}

To pilot-test the COER cyberseminar process and format, we collaborated with leadership at the Kaiser Permanente Care Management Institute (CMI). CMI is responsible for creating and maintaining evidence-based clinical practice guidelines for Kaiser Permanente. Each guideline has a guideline development team (GDT) that comprises a clinical operations lead, methodologist, and representatives from each region. The GDT is responsible for creating operationalizable guidelines at the national level that then are disseminated to stakeholders at the regional level in various areas (e.g., implementation, quality, IT) for their input and approval. The guideline is meant to serve as a minimum standard for clinical practice, such that each region may implement more than the recommended care if wanted. Each region is responsible for implementing the guideline into practice. We invited the GDT and representatives from regional implementation to participate in the interactive cyberseminar.

EPC representatives initiated the project by establishing a partnership with key individuals at Kaiser Permanente CMI: the Senior Manager of Evidence Services and the Medical Director of the Center for Clinical Information Services, both of whom oversee the National Guideline Program, as well as a methodologist and an evidence analyst in the National Guideline Program who are responsible for diabetes-related guidelines (see Process Description). The methodologist is a clinician with expertise in clinical epidemiology, whose role is to frame the question(s) and assist the evidence analyst in conducting and interpreting systematic reviews for the GDT. The evidence analyst provides both scientific support and administrative support to the GDT.

We chose these four partners because of their unique vantage point: they understand both the EPC product and the evidence needs of the health system, frequently utilizing EPC reports and conducting evidence reviews to support the National Guideline Program. Our health system partners facilitated the identification of the topic and EPC report of interest, and they served as liaisons to other key individuals within Kaiser Permanente throughout the project. Both the methodologist and evidence analyst served as our primary collaborators in developing, administrating, and evaluating the cyberseminar.

\section{Process Description}

This project spanned several months (Table 1). We initially contacted our key partners in September 2017. At this time, they expressed an interest in cardiovascular-related (including diabetes) topics. We provided them with a list of 13 recent cardiovascular EPC reports, from which the cardiovascular clinical leads identified the report most relevant to their work. The leads selected the systematic review in support of the USPSTF recommendation on screening for abnormal glucose conducted by the Pacific Northwest EPC. ${ }^{5}$

We interviewed our CMI partners to learn why they selected the report. We then developed a draft of the cyberseminar and engaged the methodologist for the diabetes GDT to ascertain the team's evidence needs. She provided feedback on the format and focus of the cyberseminar, contributed content and slides for it, and volunteered to moderate the session. Next, we worked with our CMI and GDT partners to identify relevant regional stakeholders outside of the 
guideline team, and to identify pre-seminar questions relevant to guideline or post-guideline decision-making. These questions helped frame the cyberseminar agenda and discussion.

After agreement was reached on the basic content, we refined the content and slides over an approximately 1-month period. During this time, we worked with the evidence analyst to identify a date/time for the cyberseminar that would work for all core GDT members and invited Kaiser Permanente national and regional partners whose primary focus was implementation. The evidence analyst hosted the cyberseminar and distributed pre-meeting materials and post-meeting surveys.

Table 1. Project timeline

\begin{tabular}{|c|c|}
\hline Date & Methods Project Activity \\
\hline $\begin{array}{l}2017 \\
\text { Sep }\end{array}$ & Initial contact to establish relationship with Kaiser Permanente \\
\hline Oct & Development of core concept of COER cyberseminar \\
\hline Nov & $\begin{array}{l}11 / 29 / 17 \\
\text { Kaiser Permanente identification of EPC report of interest }\end{array}$ \\
\hline Dec & $\begin{array}{l}\text { 12/21/17 } \\
\text { Kickoff call with Kaiser Permanente }\end{array}$ \\
\hline $\begin{array}{l}2018 \\
\text { Jan }\end{array}$ & $\begin{array}{l}\text { 1/5/18 } \\
\text { Consultation with Kaiser Permanente methodologist } \\
1 / 17 / 18 \\
\text { Scheduled cyberseminar and invited attendees }\end{array}$ \\
\hline Feb & $\begin{array}{l}2 / 12 / 18 \\
\text { Cyberseminar } \\
2 / 28 / 18 \\
\text { Debrief call with key partners }\end{array}$ \\
\hline Mar & $\begin{array}{l}3 / 5-3 / 23 / 18 \\
\text { Survey of cyberseminar participants }\end{array}$ \\
\hline Apr & $\begin{array}{l}4 / 15 / 18 \\
\text { Submitted draft report }\end{array}$ \\
\hline
\end{tabular}




\section{Evaluation Methods}

Our evaluation focused on three areas: (1) the content and usefulness of the EPC report within a clinical operations guideline and implementation process; (2) the usefulness of the cyberseminar, including the identification of evidence presentation elements that were most helpful and improvements that should be made; and (3) the extent to which the process was likely to inform decision-making at Kaiser Permanente.

We primarily used two data sources to evaluate the EPC report and the cyberseminar:

1) Interview with our key partners. Following the cyberseminar, we developed an interview guide to evaluate the EPC report, the process used to develop the cyberseminar, and the cyberseminar itself. We used the guide in a conference call debriefing with the four CMI and GDT partners (Appendix A).

2) Survey of several cyberseminar participants. We developed a short, online, post-panel survey. The evidence analyst sent the survey to nine cyberseminar participants (Appendix B). We surveyed three GDT members and six implementation and/or quality leads. We intentionally surveyed people who not only represented each of the eight regions but could reflect the national perspective.

In addition to the formal interview and survey, we took minutes of all phone calls with Kaiser Permanente partners. We also documented participant discussion and questions during the cyberseminar itself.

\section{Results}

\section{Final Product Description}

The COER cyberseminar was a 1-hour, interactive, web-based presentation and discussion hosted by CMI and facilitated by the Kaiser Permanente methodologist for the diabetes GDT. Information was co-presented by EPC representatives and the methodologist (Appendix C).

The cyberseminar was developed to communicate the findings from the evidence report and to facilitate a discussion about the evidence and relevant context. The aim of the cyberseminar was to help the GDT update its clinical practice guidelines about diabetes prevention and facilitate the implementation of evidence-based interventions in Kaiser Permanente clinics. Clinical leads with CMI selected the specific EPC report because they were in the process of updating their guidance on diabetes prevention when we made our initial contact.

The GDT indicated that a focus on evidence from an EPC report on pharmacologic and nonpharmacologic treatment of prediabetes to prevent (or delay) the onset of diabetes would be particularly helpful. One of our key partners at CMI, the methodologist, also informed us that this topic was particularly relevant because in April 2018, Medicare began covering the Diabetes Prevention Project (DPP), which is an intensive lifestyle behavioral intervention to prevent diabetes. Many Kaiser Permanente regions had already begun to develop and offer intensive lifestyle behavioral interventions to their members.

The presentation consisted of a high-level summary and description of the systematic review evidence; comparison of this systematic review with other systematic reviews identified and used by the GDT; a description of implementation issues for lifestyle interventions included in the systematic review (e.g., training needed, mode of delivery, intensity/number of contacts); a review of CMS reimbursement for lifestyle interventions; and a discussion about issues/considerations pre-identified in collaborations with the diabetes GDT leadership. 
The cyberseminar had three main objectives.

1) Engage stakeholders from multiple disciplines and levels of leadership early in the process of attaining an understanding of the evidence to improve downstream implementation. After selecting the EPC report of interest, CMI leadership determined that the diabetes GDT was the appropriate audience for the cyberseminar. Our understanding was that the GDT typically formulates its evidence-based guidance, then this guidance is circulated to a larger group of stakeholders (e.g., implementation, IT, and quality representatives at the regional level) in a second round of approval. We aimed to include and engage this larger group of stakeholders by introducing them to the key evidence earlier in the process. Our partners at Kaiser Permanente supported our approach and helped to identify and invite these individuals. Twenty-nine of 45 people invited attended the cyberseminar. Participants included a mix of diabetes GDT members, national and regional representatives working on implementation of lifestyle interventions, and primary researchers studying the implementation of lifestyle interventions at the regional level. Participants were a mix of clinicians (including nurses) and administrators.

2) Be interactive rather than didactic. We developed pre-seminar questions that we distributed about a week before the seminar to "prime" the audience for engaged listening and to get them thinking about the relevance of the evidence to their clinical context (Appendix D). We also maximized discussion time by limiting the presentation of the evidence to focus on key decision points, and by facilitating discussion through the conference call line or online chat boxes, with the methodologist as the facilitator for the session. In our initial consultation with the methodologist, we obtained guidance to keep the evidence focused at a high level and limited to no more than 20 minutes; we were advised as to which key question (of the eight questions) addressed in the EPC report we should focus on.

3) Deliver the evidence in a context relevant to our stakeholders; thus, be a collaborative and iterative process. The KPRA EPC had an existing relationship with CMI leadership and the methodologist who facilitated the discussion. From the selection of the EPC report of interest to the development of the cyberseminar itself, we aimed to solicit and incorporate our partners' experience and expertise. The methodologist briefed us on the process to date and the evidence sources the diabetes GDT had used for their decisionmaking prior to the identification of the selected EPC report. Thus, we were able to compare results of the previously considered evidence to the EPC report findings and identify the relevant information in the review that addressed specific implementation concerns. We shared draft versions of our slides and cyberseminar content with our key partners and the two clinical leads of the diabetes GDT. By doing this, we were able to tailor the presentation to other specific needs, for example, include an emphasis on implementation issues related to the DPP intervention and a focus on the evidence (and evidence gaps) regarding virtual interventions.

\section{Organizational Context}

To determine the potential applicability of findings to other organizations, it may be helpful to consider key aspects of Kaiser Permanente's structure and operational readiness. Kaiser Permanente is a national, hierarchical nonprofit organization with a long history as a staff model- 
managed care organization. Permanente physicians traditionally have held a strong role within the organization in developing and determining the appropriateness of clinical policy.

Permanente physicians also may be different from those in other health care organizations; for example, may have a stronger social justice orientation than network model-managed care physicians. ${ }^{6}$ Kaiser Permanente has both strong national and regional structures, with each region functioning independently. The national organization sets guidelines for minimum care expected, giving each region flexibility in implementing guidelines tailored to their local resources and needs. Kaiser Permanente also has a mature, robust IT infrastructure for delivery of care, as well as for communication and dissemination of information between national and regional entities. The effects of these components on readiness for the cyberseminar are unknown.

The value Kaiser Permanente places on evidence-based care and its mature clinical guideline development process, highly developed national and regional structures, and robust IT systems should facilitate its adoption of the cyberseminar approach. ${ }^{1}$ On the other hand, it might be more difficult for Kaiser Permanente and similarly structured organizations to implement care based on an evidence review than for smaller organizations (e.g., without a national and regional structure, or multiple regions). As with any large organization, the size of the health system, established procedures, and management silos that may separate clinical professions or disciplines could create challenges for an interdisciplinary, multi-level interactive process.

Interviews with our key partners revealed that the most critical factor in selecting the EPC report was synchrony with ongoing work by the GDT to update their existing guidance on screening and preventing diabetes, such that the deep dive we would provide into the evidence would be available "just in time" to existing committees and workgroups. In addition to the organizational structure specific to Kaiser Permanente, there may also be external factors that affect the generalizability of our project to other topics, EPC reports, and health systems. Most notably in this pilot, one external factor that created a "burning platform" for Kaiser Permanente's focus on screening for diabetes at this time was the newly available funding from Medicare to cover lifestyle diabetes-prevention programs. This coverage was discovered in conversations with key partners during the development of the cyberseminar. One interviewee noted that the topic came at a unique point in time because of an impending mandate for CMS coverage, so people were already working to implement programs. This scenario may not be common for the clinical focus of most AHRQ reports.

\section{Evaluation Results}

\section{Evaluation of the Cyberseminar}

According to the methodologist, the COER cyberseminar served the evidence need of the GDT in its decision-making process. The general sentiment of the interviewees was that the cyberseminar went well and that participants were engaged and asked good questions.

Three aspects of the cyberseminar were novel. First was the involvement of a broader group of stakeholders early in the guideline development process, including, for example, administrators and clinician representatives from each region and from multiple organizational levels. We found that in general, guideline leaders found involvement of a broader audience at an early stage to be useful but possibly confusing. An interviewee stated that hearing from people working in implementation in the various Kaiser Permanente regions altered the recommendations developed by the GDT. Another noted that bringing together people from 
different areas of the organization was confusing, and that organizational politics needed to be acknowledged when trying something new.

Second was the shift from a report on the evidence to implementation. We heard that focusing on implementation considerations for the interventions featured in the EPC report was very helpful. Regarding the EPC report itself, interviewees noted that summarizing which of the included interventions are most ready for implementation (e.g., robust findings, replicated) would be particularly helpful and could be highlighted in evidence review reports. One interviewee noted that cyberseminar content needs to be flexible because a straight accounting of the evidence is not helpful. Another interviewee stated that the discussion of how the evidence in this review compared with other systematic reviews the GDT was using was very helpful. One person noted that because the selected EPC report was conducted in support of a USPSTF recommendation, including a summary of how the evidence was translated into the USPSTF recommendation would be of value.

The third unique aspect was the use of a formally structured interactive process, including pre-seminar questions, to link evidence review expertise to the expertise of the stakeholder group. We addressed each of these issues in our interviews. As mentioned above, interviewees felt there was a high level of engagement, noting that providing a variety of ways in which audience members can participate is helpful due to preferences in communication styles (online chat or speaking on the conference line during the presentation, sending follow-up email messages after the presentation). Interviewees felt that the pre-seminar questions were not particularly helpful because people were unlikely to spend time beforehand to read or think about the questions. Overall, the value in identifying the critical clinical questions and crafting the preseminar questions was helpful in developing the structure and content of the cyberseminar, although they may not have been used by participants.

An unanticipated part of the cyberseminar's interactive structure was that participants continued to ask for additional review information through the online chat function or email after the presentation, indicating interest and engagement in the evidence report. For example, one person involved with implementation wanted to know whether the evidence differed by racial/ethnic subgroups. The evidence reviewer (JL) answered these queries.

\section{Evaluation of the EPC Report}

Interviewees said EPC reports are a trusted source. Comments about the EPC report emphasized the high quality of these reviews and well-organized structure allowing ease of access to information on patient populations studied. They also noted that the availability of the full report on the AHRQ website was very helpful, contrasting it to systematic reviews available in manuscript-only format which lack the full level of detail needed for their decision-making process. Interviewees said evidence reviews that are not tied to a guideline, as the USPSTF report was, are less helpful for health systems, which suggests that reviews linked to recommendations (or that offer recommendations) are seen as more helpful than reviews that only provide a summary of the evidence. Additionally, one interviewee stated that USPSTF reviews are helpful to health systems because their scope is directly applicable to the systems.

Interviewees offered several observations and suggestions that were applicable to EPC reports in general. They noted that the report selected had been overlooked previously by the CMI project team when updating its guidelines because its title did not fully describe the scope of the review). They also wanted more information about subgroups, including notes about when 
subgroup data are not available, so that readers would know when data for specific subgroups do not exist versus were not considered.

Other information or questions that interviewees felt were not adequately covered in EPC reports centered on monitoring (e.g., how and how often should someone getting the intervention/treatment studied be monitored?). In addition, interviewees noted that information on interventions that are ready for implementation (e.g., robust data for benefit and replicated) could be better described and highlighted in evidence review reports. Last, our interviewees advocated for health system participation in the scoping of evidence reviews, noting that if an EPC report does not include an important piece of information in the framework of the review that the health system needs, it is too late at the dissemination phase to modify the scope. Health systems would need to engage with the process at the beginning of the EPC project.

\section{Participant Survey Results}

Of the nine participants surveyed, only three responded, despite receiving email reminders. Respondents rated the cyberseminar as "good" (2) or "excellent” (1). They thought that interactively engaging national or regional clinical policy, guideline, or program developers with evidence reviewers in this type of cyberseminar was desirable. Two respondents endorsed including inter-professional stakeholders (e.g., leaders in primary care, specialty care, patient representatives).

Only two respondents answered all the survey questions. Both thought that all the key features of the cyberseminar that we presented to them were somewhat or very important, and mostly very important. These features were:

- Relevance to upcoming policy or program development

- Stakeholder representation with goals developed in partnership between evidence review scientists and clinical, administrative, and policy or program leaders

- Scheduling the cyberseminar early in the development of policies or programs

- Providing a rapid response to address questions arising during the cyberseminar

- Having evidence review scientists provide an in-depth evidence review at the start of the cyberseminar

- Giving participants sufficient time to ask questions and make suggestions

- Giving participants pre-seminar questions highlighting policy or program decisions to be informed by the cyberseminar

- Providing access to both chat box and audio interaction.

The two respondents found the length of the presentation, the amount of material covered, and the depth of the material covered to be about right. Finally, respondents found that it was somewhat or extremely important for funders of systematic evidence reviews to learn about and address implementation issues relevant to health care organizations.

\section{Discussion}

\section{Value and Applicability to Other Health Systems}

Overall the COER cyberseminar went smoothly and was well received. It met the stated aims of facilitating adoption of an EPC report's findings by an organization's clinical practice guideline team and linking a variety of clinical operations decision-makers at national and regional levels to the evidence (and evidence reviewers). 
Several key factors and drivers made this pilot cyberseminar useful and may be important when considering its implications for future use.

1) Timing and organizational readiness are critical. The primary reason the cyberseminar process was well received is that the topic (and EPC report) was identified as relevant by the health care organization. The organization was in the process of updating the guideline on the topic the chosen review addressed, and the organization's regions faced immediate implementation decisions. Our interview and survey respondents found the cyberseminar useful for informing decision points around whether and how to adopt the evidence in the chosen evidence review. Based on our experience, the EPC program may benefit from better methods for responding to organizational decision-makers with relevant review information.

2) The cyberseminar required the health care organization's participation and the evidence reviewers' responsiveness to the organizational needs. To make the partnership work, the health care organization needed to articulate and frame its evidence needs within the context of its decision-making. The KPRA EPC had existing relationships with a few of the key partners, who helped to facilitate the development and conduct of the cyberseminar. While existing relationships may not be requisite, developing and investing in a relationship with the health care organization is a critical factor in building a collaborative approach, and requires multiple touches throughout the process. Ideally, a partnership should begin early in the process. Our process (not including the evaluation process) involved about four conference calls and email communication over a 2-month time frame. Having the health care organization host or co-facilitate a cyberseminar may be important in establishing engagement, credibility, and acceptability of the information being conveyed. Working with the health care organization to hone the presentation is also critical to distill the correct information into an accessible format for their organization's culture. Based on our experience, the EPC program may benefit from identifying methods for partnering with health care organizations and investing resources to foster these partnerships (i.e., providing a network and infrastructure to support partnerships with interested health care organizations).

3) Cyberseminars need to place the evidence from the EPC report in a larger context; it is not simply to present a summary of the evidence at a high level. The cyberseminar we conducted presented the evidence at a very high level accessible to decision-makers with differing levels of familiarity with the evidence. Based on our knowledge of the context of the health care organization's readiness and actions around this topic, as well as external drivers (i.e., impending mandate for Medicare coverage), we knew to also address how the EPC report findings compared with existing systematic reviews, how the effective interventions compared with the DPP, if any of the effective interventions were virtual interventions, and what the implementation considerations were around a complex lifestyle intervention like the DPP. Providing this information went beyond the information found in the EPC report itself. Our health system partner found the deeper dive into details on implementation-ready interventions very helpful. We also needed to be responsive to follow-up questions that could be addressed by the existing evidence in real time (i.e., during the cyberseminar or immediately following). The EPC program may need to consider the resource implications of the EPC reviewers serving as experts (evidence chaperones) for organizations wishing to use EPC results. 
4) The cyberseminar provided a way for evidence reviewers to link decision-makers to people who will be directly working on implementation of the decisions. The decisionmakers found that having access to evidence reviewers in combination with the conversation and insights from people at the implementation level was very useful and reported that this process influenced their decision-making. The EPC program may want to consider further development of methods for enabling simultaneous feedback from decision-makers, implementers, and evidence review experts, recognizing that those implementing the evidence and making the decision to implement the evidence are often separate groups of individuals.

\section{Lessons Learned and Applicability for Other EPC Reports}

In general, our health care-organization partner values EPC reports, and finds them to be trusted, well-conducted resources, and preferable to other systematic reviews. The organization expressed an interest in becoming involved at the beginning of the EPC review process to ensure that these reports meet the health system's needs. In developing the cyberseminar and soliciting feedback from the health care organization, we also recorded observations that may help facilitate the adoption of EPC reports (and their findings) into clinical practice. EPC reports often include a number of key questions, and the title and/or abstract of the review may not be descriptive of all the evidence addressed in the report, which may cause it to be overlooked. EPC reports that make "recommendations" or are paired with guidelines are more helpful to health systems.

The EPC report we used in developing the cyberseminar lacked a robust evaluation of harms of the intervention, longer-term observation follow-up, details about implementation-ready interventions (e.g., transparency around interventions delivered), and details about populations studied and evidence specific to clinically relevant subpopulations. Such limitations may be common in other EPC reports. EPC reports often do not place the evidence in a larger context; for example, policy/coverage considerations, implementation and monitoring considerations, and cost/resource implications. Health care organizations may rely on multiple related systematic reviews (or data sources) in their decision-making process. While EPC reports often include a discussion of its findings in the context of other existing systematic reviews, this may be done in a somewhat cursory fashion. A detailed analysis of the overlap and nonoverlap between reviews and the reasons for data congruence and noncongruence may be necessary when the health care organization partner has identified/used other existing systematic reviews. While addressing each of these limitations may not always feasible, health care organizations nonetheless require this information in their decision-making process. Partnerships with health care organizations in addition to content experts (e.g., technical expert panel) may be helpful in identifying critical contextual framing considerations.

\section{Conclusion}

Our pilot project demonstrated the utility of a dynamic format to link evidence (and evidence reviewers) to a variety of clinical operations decision-makers and people involved in implementation of a clinical service. While the cyberseminar is a promising way to connect key stakeholders in a health system with evidence reviews, its development and implementation require a partnership between the reviewers and these stakeholders. The timing of the information depends on the decisional context of the health care organization (i.e., readiness), which can, again, best be known by collaborating with the health care organization. Knowing the 
critical details of the evidence to communicate also depends on understanding the larger clinical or policy context, which may or may not be specific to an individual health care organization.

While EPC reports can never comprise all the information that health care organizations need to determine whether and how to implement the evidence, involving them early in the systematic review process may be an important step in improving their utility to these end-users. We believe that AHRQ's EPC program can support networks and provide infrastructure (funding, dedicated time) to develop these requisite partnerships with interested health system partners. 


\section{References}

1. Rogers EM. Diffusion of Innovations. Fourth Edition. New York, NY: The Free Press; 1995.

2. Kessler R, Glasgow RE. A proposal to speed translation of healthcare research into practice: dramatic change is needed. Am J Prev Med 2011 Jun;40(6):637-44. PMID: 21565657. doi: 10.1016/ j.amepre.2011.02.023.

3. van de Ven AH, Johnson PE. Knowledge for Theory and Practice. Acad Manage Rev 2017 Nov;31(4):802-821. doi.org/10.5465/amr.2006. 22527385.

4. Campbell D, Redman S, Jorm L, et al. Increasing the use of evidence in health policy: practice and views of policy makers and researchers. Aust New Zealand Health Policy 2009 Aug 24;6(21). PMCID: PMC2739528. doi.org/10.1186/1743-84626-21.
5. Selph S, Dana T, Bougatsos C, et al. Screening for Abnormal Glucose and Type 2 Diabetes Mellitus: A Systematic Review to Update the 2008 U.S. Preventive Services Task Force Recommendation. Rockville (MD): Agency for Healthcare Research and Quality (US); 2015 Apr. Evidence Syntheses, No. 117. PMID: 25973510. https://www.ncbi.nlm.nih.gov/books/NBK2 93871/

6. Meredith LS, Rubenstein LV, Rost K, et al. Treating depression in staff-model versus network-model managed care organizations. J Gen Intern Med 1999;14(1):39-48. PMCID: PMC1496436. doi: 10.1046/j.1525-1497.1999.00279.x 


\section{Appendix A. Interview Guide}

1) Was the content of the EPC report and/or presentation helpful? Was any information missing?

a. What other evidence do you need to know to inform your decision-making process? (two-fold decision making process - Guideline Development Team decision and implementation decisions)

i. Deeper dive into individual studies? Longer-term follow-up of studies? Coverage decisions? Harms or other trade-offs?

2) What in the seminar went well? And what can be improved?

a. Are there elements of the seminar that could/should be replicated?

b. Were any elements of the seminar distracting, superfluous, or problematic?

c. Were the pre-seminar questions and/or embedded questions in the presentation helpful?

d. Was inviting a broad audience from the Guideline Development Team to primary researchers to individuals responsible for implementation helpful?

3) To what extent did the seminar influence or inform the decision-making process at KP?

a. What would it take to make this seminar applicable to other organizations?

i. Are there organizational factors, i.e., aspects of readiness, at play?

ii. Was our existing relationship a necessary component to making this work?

b. Are there additional steps that you need participation from the evidence reviewers for decision-making? 


\section{Appendix B. Prediabetes Interactive Evidence Review Cyberseminar Survey}

You recently attended an interactive evidence review cyberseminar focused on interventions to delay the onset of diabetes. We are very interested in your views both of the seminar and more generally about how evidence from the literature can best be used to support clinical programs and policies.

1. Overall, how would you rate the interactive evidence review cyberseminar you attended?
( ) Excellent
() Good
() Fair
() Poor

2. If carried out well, is an interactive evidence review seminar that includes relevant clinical policy, guideline, and program stakeholders a desirable approach for engaging evidence review scientists with

$\begin{array}{llll}\begin{array}{l}\text { National or regional clinical policy, guideline, or } \\ \text { program developers? }\end{array} & \text { () No } & \text { () Maybe } & \text { () Yes } \\ \begin{array}{l}\text { Inter-professional stakeholders (e.g., physicians, } \\ \text { nurses, administrators)? }\end{array} & \text { () No } & \text { () Maybe } & \text { () Yes } \\ \text { Front-line primary care site leaders or champions)? } & \text { () No } & \text { () Maybe } & \text { () Yes } \\ \begin{array}{l}\text { Front-line clinical program leaders or champions } \\ \text { other than primary care? }\end{array} & \text { () No } & \text { () Maybe } & \text { () Yes } \\ \text { Patient representatives? } & \text { () No } & \text { () Maybe } & \text { () Yes }\end{array}$

3. Based on your experience, which of the following features can enhance the success or usefulness of an interactive evidence review cyberseminar?

$\begin{array}{lccc}\begin{array}{l}\text { The seminar focuses on an upcoming policy or } \\ \text { program development process in your organization }\end{array} & \begin{array}{c}\text { () Very } \\ \text { important }\end{array} & \begin{array}{c}\text { () Somewhat } \\ \text { important }\end{array} & \begin{array}{l}\text { () Not important } \\ \text { or Not Applicable }\end{array} \\ \begin{array}{l}\text { Cyberseminar participants represent all major } \\ \text { stakeholder groups involved in implementing the } \\ \text { findings of the evidence review in our organization }\end{array} & \begin{array}{c}\text { () Very } \\ \text { important }\end{array} & \begin{array}{c}\text { () Somewhat } \\ \text { important }\end{array} & \begin{array}{l}\text { () Not important } \\ \text { or Not Applicable }\end{array}\end{array}$

The specific goals for the cyberseminar are developed in partnership between evidence review scientists and clinical or administrative policy or () Very () Somewhat () Not important program leaders from your organization important important or Not Applicable

The evidence-review cyberseminar occurs early in the development of new major policy or program initiatives

$\begin{array}{ccc}\text { () Very } & \text { () Somewhat } & \text { () Not important } \\ \text { important } & \text { important } & \text { or Not Applicable }\end{array}$




$\begin{array}{lccc}\begin{array}{l}\text { Evidence review scientists perform rapid, } \\ \text { responsive review to address questions arising } \\ \text { during the cyberseminar }\end{array} & \begin{array}{c}\text { () Very } \\ \text { important }\end{array} & \begin{array}{l}\text { () Somewhat } \\ \text { important }\end{array} & \begin{array}{l}\text { () Not important } \\ \text { or Not Applicable }\end{array} \\ \begin{array}{l}\text { Evidence review scientists provide an in-depth } \\ \text { evidence overview of the chosen evidence review(s) } \\ \text { at the start of the seminar }\end{array} & \begin{array}{c}\text { () Very } \\ \text { important }\end{array} & \begin{array}{c}\text { () Somewhat } \\ \text { important }\end{array} & \begin{array}{l}\text { () Not important } \\ \text { or Not Applicable }\end{array} \\ \begin{array}{l}\text { Cyberseminar participants have sufficient time to } \\ \text { ask questions and make suggestions }\end{array} & \begin{array}{l}\text { () Very } \\ \text { important }\end{array} & \begin{array}{l}\text { () Somewhat } \\ \text { important }\end{array} & \begin{array}{l}\text { () Not important } \\ \text { or Not Applicable }\end{array} \\ \begin{array}{l}\text { Cyberseminar participants receive pre-seminar } \\ \text { questions highlighting policy- or program-related } \\ \text { decisions to be informed by the seminar }\end{array} & \begin{array}{c}\text { () Very } \\ \text { important }\end{array} & \begin{array}{c}\text { () Somewhat } \\ \text { important }\end{array} & \begin{array}{l}\text { () Not important } \\ \text { or Not Applicable }\end{array} \\ \begin{array}{l}\text { The cyberseminar platform allows for telephone- } \\ \text { based interaction with participants }\end{array} & \begin{array}{c}\text { () Very } \\ \text { important }\end{array} & \begin{array}{c}\text { () Somewhat } \\ \text { important }\end{array} & \begin{array}{l}\text { () Not important } \\ \text { or Not Applicable }\end{array} \\ \begin{array}{l}\text { The cyberseminar platform allows for chat-box } \\ \text { interaction with participants }\end{array} & \begin{array}{c}\text { () Very } \\ \text { important }\end{array} & \begin{array}{c}\text { () Somewhat } \\ \text { important }\end{array} & \begin{array}{l}\text { () Not important } \\ \text { or Not Applicable }\end{array}\end{array}$

\section{Based on your experience participating in the recent interactive evidence review cyberseminar on interventions for delaying the onset of diabetes, rate the following aspects of the evidence review presentation:}

The length of the presentation (in this case, 20 minutes)

$\begin{array}{lll}\text { () Too much () Too little } & \text { () About right }\end{array}$

The amount of material covered (e.g., evidence on lifestyle and medications to delay the onset of diabetes)

() Too much ( ) Too little ( ) About right

Depth of information covered (e.g., details on lifestyle and medications studied)

$\begin{array}{lll}\text { () Too much () Too little } & \text { () About right }\end{array}$

5. How important is it for funders of systematic evidence reviews (such as the one covered in the evidence review cyberseminar you attended) to learn about and act on issues related to implementing evidence review information in healthcare organizations such as yours?
() Extremely important
( ) Somewhat important
() Not so important

6. Please enter any general comments here: 


\title{
Appendix C. Cyberseminar Slides and Presentation Notes
}

\section{Understanding the Evidence for Medication and Lifestyle Interventions to Delay the Onset of Diabetes}

\author{
February 12, 2018
}

Jennifer Lin, Lisa Rubenstein, and Tracy Beil

Kaiser Permanente Research Affiliates (KPRA) and Southern California (RAND) EPCs

Facilitated by Beth Liles 


\section{Presenters}

Jennifer Lin, MD, MCR, FACP

Director, KPRA Evidence-based Practice Center

Investigator, Kaiser Permanente Center for Health Research

General Internist, Northwest Permanente

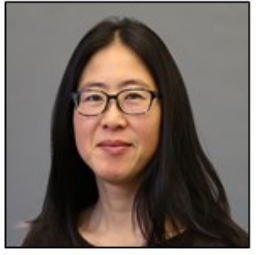

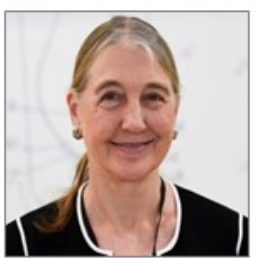

Lisa Rubenstein, MD, MSPH

Director, VA Quality Scholars Program at Greater Los Angeles

Director, VA QUERI Center for Implementation Practice \& Research Support

Professor of Medicine and Public Health at VA Greater Los Angeles and UCLA

Senior Natural Scientist at RAND

Tracy Beil, MS

Project Director, KPRA Evidence-based Practice Center

Research Program Manager

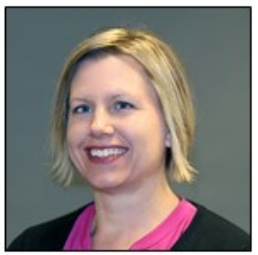

\section{The speakers have no conflicts of interest to report.}




\section{Genesis and purpose of this seminar}

- $A H R Q$-funded effort to try to improve the uptake/use of evidence reports conducted by Evidence-based Practice Centers (EPC) by health care delivery systems - Joint effort with KPRA EPC, RAND EPC and KP CMI

- Interactive format to link reviews (evidence reviewers) to a broad range of stakeholders within KP- those developing clinical guidance and those implementing clinical guidance

- This seminar consists of a brief evidence presentation with ample time for discussion 


\section{Systematic review of interest}

\section{Evidence Synthesis}

\section{Number 117}

\section{Screening for Abnormal Glucose and Type 2 Diabetes Mellitus: A Systematic Review to Update the 2008 U.S. Preventive Services Task Force Recommendation}

AHRQ Publication No. 13-05190-EF-1 April 2015

Selph S, Dana T, Bougatsos C, Blazina I, Patel H, Chou R. Screening for Abnormal Glucose and Type 2

Diabetes Mellitus: A Systematic Review to Update the 2008 U.S. Preventive Services

Task Force Recommendation. Rockville (MD): Agency for Healthcare Research and Quality (US); 2015 Apr. Report No: 13-05190-EF-1. PMID: 25973510

Final Recommendation Statement: Abnormal Blood Glucose and Type 2 Diabetes Mellitus: Screening. U.S. Preventive Services Task Force. November 2016

U.S. Preventive Services

TASK FORCE

\section{Horne}

Recommendations

Published Fina: Recommendations

Recommendations in

Progress

Copyright Notice

Information for Health Professionals

Information for

Consumers

Public Comments and Nominations
You are here: Home 》 Recommendations for Primary Care Practice 》 Search Recommendation Abnormal Blood Glucose and Type 2 Diabetes Mellitus Release Date: October 2015

\section{Recommendation Summary}

\begin{tabular}{|l|l|l||}
\hline Population & Recommendation & $\begin{array}{l}\text { Grade } \\
\text { (Whars } \\
\text { This?? }\end{array}$ \\
\hline $\begin{array}{l}\text { Adults aged } 40 \text { to } \\
70 \text { years who are } \\
\text { Overweight or } \\
\text { obese }\end{array}$ & $\begin{array}{l}\text { The USPSTF recommends screening for abnormal } \\
\text { blood glucose as part of cardiovascular risk } \\
\text { assessment in adults aged } 40 \text { to } 70 \text { years who are } \\
\text { overweight or obese. Clinicians should offer or refer } \\
\text { patients with abnormal blood glucose to intensive } \\
\text { behavioral counseling interventions to promote a } \\
\text { healthful diet and physical activity. }\end{array}$ & \\
\hline
\end{tabular}

Appendix C-4 


\section{Why screen?}

- USPSTF recommendation to screen for DM hinges on ability of lifestyle interventions to prevent/delay the onset of DM

- Intensive lifestyle interventions to prevent the development of diabetes consistently show a moderate benefit in reducing the progression to diabetes.

- Direct evidence that preventing a diagnosis or early identification of diabetes results in improved patient health outcomes is limited. 


\section{Key Question 7 in the systematic review}

Do interventions for impaired fasting glucose or impaired glucose tolerance delay or prevent progression to type 2 diabetes?

- Lifestyle interventions

- Medications

- e.g., metformin, thiazolidinediones, alpha-glucosidase inhibitors 


\section{As you listen to the evidence today...}

- How effective are interventions to delay or prevent the onset of diabetes?

- Do the benefits of these interventions outweigh the harms?

- What evidence do you need that is NOT covered in this systematic review?

- What else do you need to know that is not addressed? 


\section{Overall Findings for Key Question 7}

\begin{tabular}{|c|c|c|c|}
\hline & $\begin{array}{l}\text { No. } \\
\text { studies }\end{array}$ & $\begin{array}{l}\text { Summary of findings on } \\
\text { progression to diabetes }\end{array}$ & Limitations \\
\hline Lifestyle & 10 & RR $0.57(95 \% \mathrm{Cl} 0.43,0.70)$ & $\begin{array}{l}\text { Clinical } \\
\text { heterogeneity }\end{array}$ \\
\hline $\begin{array}{l}\text { Medications } \\
\text { Metformin }\end{array}$ & 3 & RR $0.69(95 \% \mathrm{Cl} 0.49,0.76)^{*}$ & $\begin{array}{l}\text { Few studies, TZD } \\
\text { high statistical }\end{array}$ \\
\hline $\begin{array}{l}\text { TZD } \\
\text { a-gluc inhibitors }\end{array}$ & $\begin{array}{l}3 \\
4\end{array}$ & $\begin{array}{l}\text { RR } 0.51(95 \% \text { Cl 0.23, 1.06) } \\
\text { RR } 0.65(95 \% \text { Cl 0.44, 0.91) }\end{array}$ & heterogeneity \\
\hline $\begin{array}{l}\text { Multifactorial } \\
\text { interventions }\end{array}$ & 2 & $\begin{array}{l}\text { No pooled analysis, no effect on } \\
\text { progression to DM }\end{array}$ & $\begin{array}{l}\text { Clinical } \\
\text { heterogeneity, } \\
\text { Imprecision }\end{array}$ \\
\hline
\end{tabular}




\section{What is the evidence on lifestyle interventions to prevent the onset of diabetes?}




\title{
Lifestyle interventions: Overlap with the review for the CDC Community Guide (Balk et al., 2015)
}

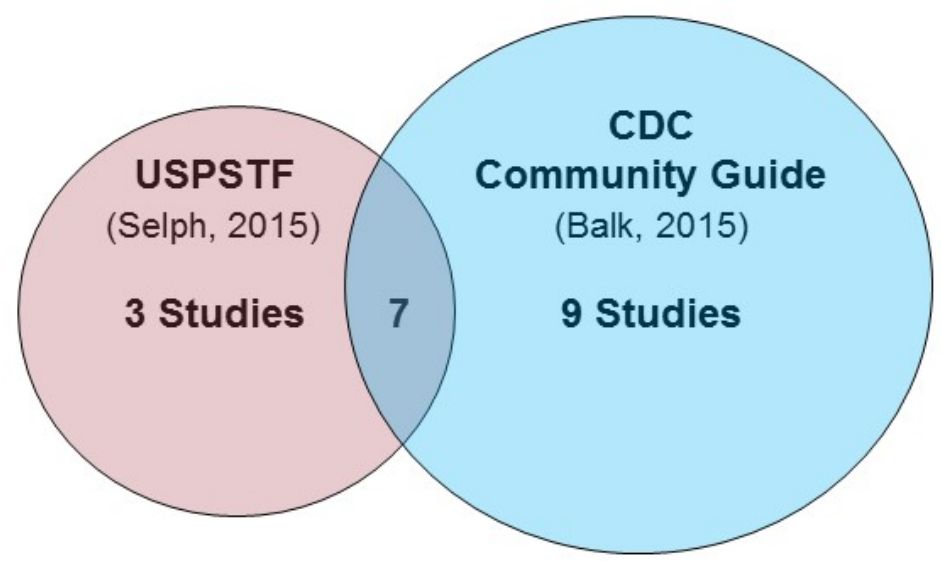

\author{
Reasons for \\ non-overlap include:
}

- Mismatch of review's search dates

- Study design

- Setting less relevant to US

- Error

Selph S, Dana T, Bougatsos C, Blazina I, Patel H, Chou R. Screening for Abnormal Glucose and Type 2 Diabetes Mellitus: A Systematic Review to Update the 2008 U.S. Preventive Services Task Force Recommendation. Rockville (MD): Agency for Healthcare Research and Quality (US); 2015 Apr. Report No.: 13-05190-EF-1. PMID: 25973510

Balk EM, Earley A, Raman G, Avendano EA, Pittas AG, Remington PL. Combined Diet and Physical Activity Promotion Programs to Prevent Type 2 Diabetes Among Persons at Increased Risk: A Systematic Review for the Community Preventive Services Task Force. Ann Intern Med 2015 Sep 15;163(6):437-51. doi: 10.7326/M15-0452. PMID: 26167912 


\section{Results for lifestyle interventions}

Study or Subgroup Participants, $n$

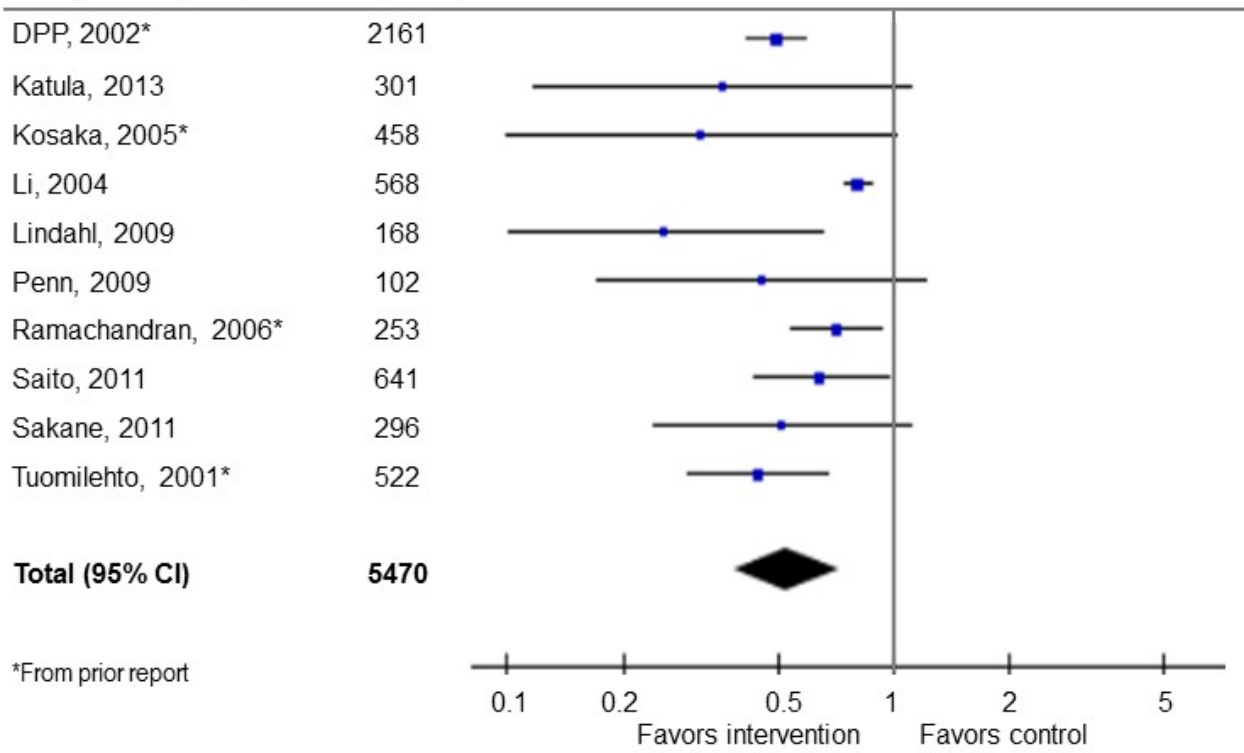

Risk Ratio

M-H, Random, $95 \%$ Cl

$0.50[0.42,0.59]$

$0.36[0.12,1.11]$

$0.32[0.10,1.01]$

$0.81[0.74,0.88]$

$0.26[0.10,0.65]$

$0.45[0.17,1.22]$

$0.71[0.54,0.94]$

$0.65[0.43,0.97]$

$0.51[0.24,1.11]$

$0.44[0.29,0.68]$

$0.53[0.39,0.72]$

Adapted from "Figure 4. Meta-Analysis of the Effect of Lifestyle Interventions on Incidence of Progression to DM". Source: Selph S, Dana T, Bougatsos C, Blazina I, Patel H, Chou R. Screening for Abnormal Glucose and Type 2 Diabetes Mellitus: A Systematic Review to Update the 2008 U.S. Preventive Services Task Force Recommendation. Rockville (MD): Agency for Healthcare Research and Quality (US); 2015 Apr. Report No.: 13-05190-EF-1. PMID: 25973510 


\section{What is the evidence on medications other than metformin to prevent the onset of diabetes?}




\section{Results for TZD}

Study or Subgroup Participants, $n$

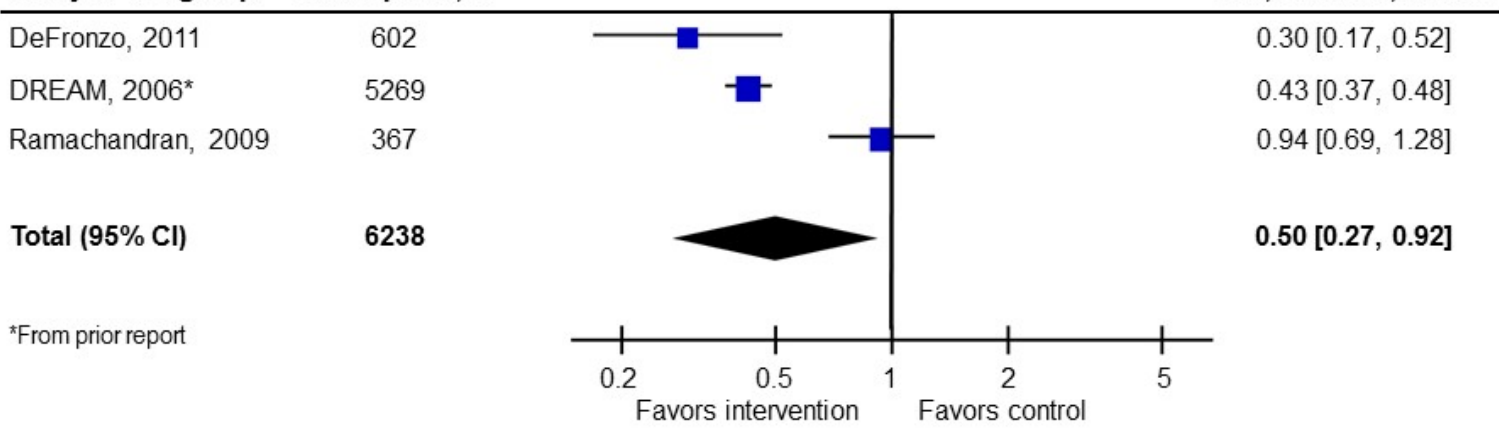

Adapted from "Figure 5. Meta-Analysis of the Effect of Thiazolidinediones on Incidence of Progression to DM". Source: Selph S, Dana T, Bougatsos C, Blazina I, Patel H, Chou R. Screening for Abnormal Glucose and Type 2 Diabetes Mellitus: A Systematic Review to Update the 2008 U.S. Preventive Services Task Force Recommendation. Rockville (MD): Agency for Healthcare Research and Quality (US); 2015 Apr. Report No.: 13-05190-EF-1. PMID: 25973510 


\section{Results for alpha-glucosidase inhibitors}

Study or Subgroup Participants, $n$

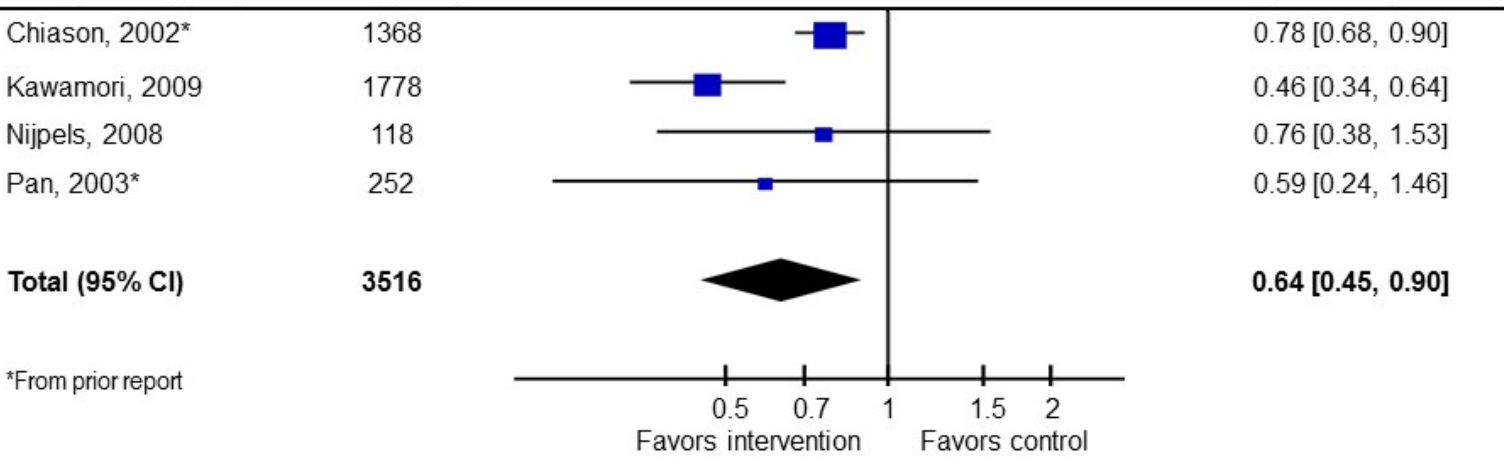

Adapted from "Figure 6. Meta-Analysis of the Effect of Alpha-Glucosidase Inhibitors on Incidence of Progression to DM". Selph S, Dana T, Bougatsos C, Blazina I, Patel H, Chou R. Screening for Abnormal Glucose and Type 2 Diabetes Mellitus: A Systematic Review to Update the 2008 U.S. Preventive Services Task Force Recommendation. Rockville (MD): Agency for Healthcare Research and Quality (US); 2015 Apr. Report No.: 13-05190-EF-1. PMID: 25973510 


\section{What about harms?}

- None of the reviews examine harms of these interventions

- While lifestyle interventions don't have any hypothesized harms, there is a cost and opportunity cost trade-off

- An examination of harms of medications is necessary to assess the net benefit for these medications (particularly their long term use) to determine their role in diabetes prevention 


\section{As you listen to the implementation issues around lifestyle interventions...}

- How far do you want to extrapolate from the evidence?

- What sort of lifestyle interventions should we be offering our members?

- Who should be offered intensive lifestyle interventions?

- What else do you want to know? 


\section{Implementation issues for lifestyle interventions- DPP as the exemplar}

- Intervention goals

- Comparison group

- Training required

- Mode of delivery

- Intensity of intervention (when and how much)

- Availability of materials

- Target population

- setting, adherence
- Goals: achieve and maintain weight reduction $\geq 7 \%$ of initial body weight through a healthy low-calorie, low-fat diet and engage in moderate-intensity physical activity for $\geq 150 \mathrm{~min} / \mathrm{wk}$

- Participants taught to record diet and exercise.

- Offered supervised exercise sessions twice per week for duration of intervention (not mandatory).

- Intervention "flexible" culturally sensitive. Lifestyle advice was tailored to the individual with emphasis on self-esteem, empowerment, and social support. 


\section{Implementation issues for lifestyle interventions- DPP as the exemplar}

- Intervention goals

- Comparison group

- Training required

- Mode of delivery

- Intensity of intervention (when and how much)

- Availability of materials

- Target population

- setting, adherence
- Intervention 2: standard lifestyle recommendations + metformin $850 \mathrm{mg}$ PO BID.

- Control: standard lifestyle recommendations + placebo pill.

- Standard lifestyle recommendations included written information with annual 20-30 minute individual session emphasizing healthy lifestyle (diet and exercise). 


\section{Implementation issues for lifestyle interventions- DPP as the exemplar}

- Intervention goals

- Comparison group

- Training required

- Mode of delivery

- Intensity of intervention (when and how much)

- Availability of materials

- Target population

- setting, adherence
- Primary care provider for recruitment only.

- Program and recruitment coordinators that were trained in motivational interviewing.

- Case manager with training in nutrition, exercise, or behavior modification (details not reported).

- Supervised exercise leader not defined. 


\section{Implementation issues for lifestyle interventions- DPP as the exemplar}

- Intervention goals

- Comparison group

- Face to face visits (individual and group).

- Training required

- Mode of delivery

- Intensity of intervention (when and how much)

- Availability of materials

- Target population

- setting, adherence 


\section{Implementation issues for lifestyle interventions- DPP as the exemplar}

- Intervention goals

- Comparison group

- Training required

- Mode of delivery

- Intensity of intervention (when and how much)

- Availability of materials

- Target population

- setting, adherence
- A case manager taught 16 one-onone sessions over 24 weeks using a curriculum which followed the Food Guide Pyramid 14.

- Subsequent sessions led by the case manager were monthly and either individual or group focused on behavior reinforcement

- 6 months core curriculum 1.8-4.6 years maintenance (mean 2.8 years).

- Optional supervised exercise sessions up to twice per week throughout intervention.

- Semiannual FBG and annual $2 \mathrm{hr}$ oral glucose tolerance test. 


\section{Implementation issues for lifestyle interventions- DPP as the exemplar}

- Intervention goals

- Comparison group

- Training required

- Mode of delivery

- Intensity of intervention (when and how much)

- Availability of materials

- Target population

- setting, adherence
- Written material: Lifestyle Manuals of Operation (www.bsc.gwu.edu/dpp).

- Modified Block Food-Frequency Questionnaire.

- Modified Activity Questionnaire.

Lifestyle Manuals of Operation. Copyright 1996; 2011; University of Pittsburgh. 


\section{Implementation issues for lifestyle interventions- DPP as the exemplar}

- Intervention goals

- Comparison group

- Training required

- Mode of delivery

- Intensity of intervention (when and how much)

- Availability of materials

- Target population

" setting, adherence
- Volunteer participants recruited through 27 (academic) US medical centers.

- Prediabetics: participant characteristics included being 25 years or older, BMI of 24 or more (22 or higher in Asians) and fasting plasma glucose of 95-125 or glucose of 140-199, $2 \mathrm{hrs}$ after $75 \mathrm{~g}$ glucose challenge.

- Adherence and retention actively fostered and used quarterly newsletters.

- $50 \%$ of the intervention group achieved weight loss goal by 24 weeks, $74 \%$ met exercise goal by 24 weeks, $72 \%$ took at least $80 \%$ of the prescribed dose of metformin. 


\section{What do we know about virtual interventions from the systematic reviews?}

- Limited evaluations of different virtual interventions

- NO trials reported on diabetes incidence as an outcome, all with shorter term follow-up

- Most informative trial evaluated face-to-face vs DVD-based intensive lifestyle intervention (12+ sessions)

- Generally high income volunteers, SF Bay area

- At 15 months, slightly larger effects on weight loss for in person than virtual, but both more than usual care group

- 2 comparative effectiveness trials evaluated virtual interventions (reality TV, internet) versus enhanced programs (with virtual counseling/interaction), found that enhanced programs resulted in weight loss at 12 months 


\section{Conclusions from the systematic reviews}

- USPSTF recommendation to screen for DM hinges on ability of lifestyle interventions to prevent/delay the onset of DM

- Using the Balk review for CDC is reasonable, more comprehensive to the USPSTF review, consistent with USPSTF review findings for lifestyle interventions

- Understanding the details of interventions is key to reproducing intervention, as deviations from the tested intervention may result in different outcomes (effectiveness) in practice

- Understanding the harms of longer term use of medications is important before implementation 


\section{YMCA program}

The YMCA Diabetes Prevention Program is for overweight adults (18+) with prediabetes, confirmed via one of 3 blood tests or has 2 or more risk factors.

The 12 month program (includes a 16 session core program followed by monthly maintenance sessions). Sessions are one hour per week and include 8 to 15 people in a group based, classroom setting.

Classroom-type settings allow for sessions to be conducted anytime or anywhere.

Participants weigh in at each session, their weight is recorded in an online tracking system, and the sessions are facilitated by a Y Lifestyle Coach (a person who is skilled in Listen First and group facilitation).

Source: $h t$ tps://www.slideshare.net/colinpowellcenter/jody-ouziel-ymca-diabetes-prevention. Judy Ouziel, Senior Executive Director, Strategic Initiatives, YMCA of Greater New York. YMCA Diabetes Prevention Program: Creating Powerful Alliances, Colin L. Powell Center, New York, NY, May 2, 2012. 


\section{Overall results}

\section{Health Care Innovation Award}

Health Care Innovation Award ( $\mathrm{HClA})$ to The Young Men's Christian Association (YMCA) of the USA (Y-USA).

Feb. 2013 - Jan. 2015
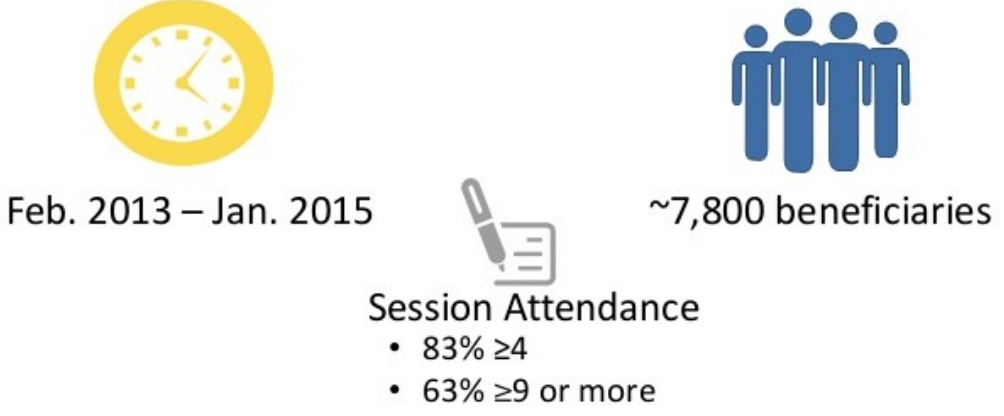

https://innovation.cms.gov/initiatives/Health-Care-Innovation-Awards/

Source: https://innovation.cms.gov/Files/slides/mdpp-overview-slides.pdf 


\section{YMCA program results}

- Among the 5,696 Medicare beneficiaries who attended four or more sessions, there was a mean weight loss of $5.27 \mathrm{~kg}(\sim 5 \%$ loss of initial weight)

- Compared to a matched cohort of 65+ prediabetic individuals in the same county (who did not enroll in DPP)

- Medicare savings

- Significantly fewer inpatient admissions and ED stays

Alva ML et.al. Health Aff (Millwood). 2017 Mar 1;36(3):417-424. 


\section{CMS reimbursement for MDPP 4/1/2018}

\section{Proposed Beneficiary Eligibility}

- Must meet Body Mass Index (BMI) Criteria:

$-\geq 25$ ( $\geq 23$ for Asian beneficiaries)

- Must have Blood Test Results:

Have within the 12 months prior to the first core session:

- Hemoglobin A1c of 5.7-6.4\%; or

- Fasting plasma glucose of $110-125 \mathrm{mg} / \mathrm{dL}$; or

- Two-hour plasma glucose of 140-199 mg/dL

- No previous diagnosis of diabetes (gestational diabetes is allowable) or End-Stage Renal Disease (ESRD).

Source: https://innovation.cms.gov/Files/slides/mdpp-overview-slides.pdf 


\section{CMS reimbursement for MDPP 4/1/2018}

- Program requirements:

- Minimum 16 core sessions in first 6 months

- Monthly maintenance sessions, second 6 months

- Monthly maintenance sessions for up to 2 years

Source: https://innovation.cms.gov/Files/slides/mdpp-overview-slides.pdf
Proposed Curriculum

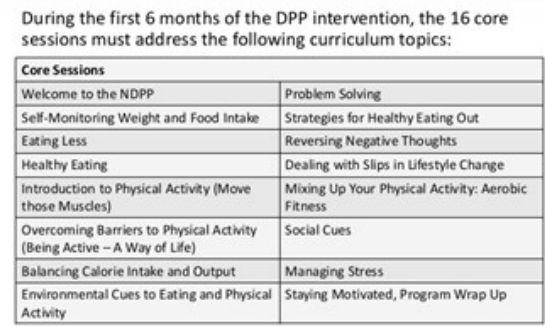

Proposed Curriculum Continued

During the second 6 months of the 12 -month Core Benefit the curriculum must address a different topic each month:

Maintenance Session Topks:

\begin{tabular}{|c|c|}
\hline Welcome to the Second thase of the provam & Strew and Time Manogement \\
\hline Healthy Gathe Taking h t Ooe Meal at a Time & 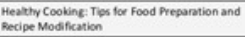 \\
\hline Making setive Choket & 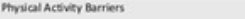 \\
\hline 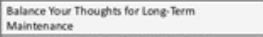 & Preventing Relapse \\
\hline Hestry Eathe Wah Variety and Blance & Hean Heoskh \\
\hline 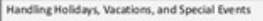 & We with Type 2 Disbetes \\
\hline 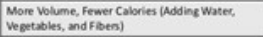 & Looking Back and Looking Forwaed \\
\hline Dietery fusts & \\
\hline
\end{tabular}

Diencarfors 


\section{Virtual sessions-CMS policy}

- (Year 1) A supplier may offer no more than 4 virtual make-up sessions within the core services period to an MDPP beneficiary,

- of which no more than 2 virtual make-up sessions may be core maintenance sessions

- (Years 2, 3) A supplier may offer no more than 3 virtual make-up sessions that are ongoing maintenance sessions to an MDPP beneficiary during any rolling 12-month time period.

- Weights can only be recorded in-person 


\section{Discussion Questions-Implementation}

- What type of lifestyle interventions should be made available?

- To whom should these lifestyle interventions be made available?

- Early insights:

- Dr.'s Fitzpatrick and Fortmann, researchers at KPCHR in Portland-evaluation study to understand the implementation of virtual and in-person diabetes prevention programs at KPNW 


\section{Discussion Questions-Implementation}

- When should metformin be offered or initiated?

- Are there medications other than metformin that may be reasonable to consider as prevention? 


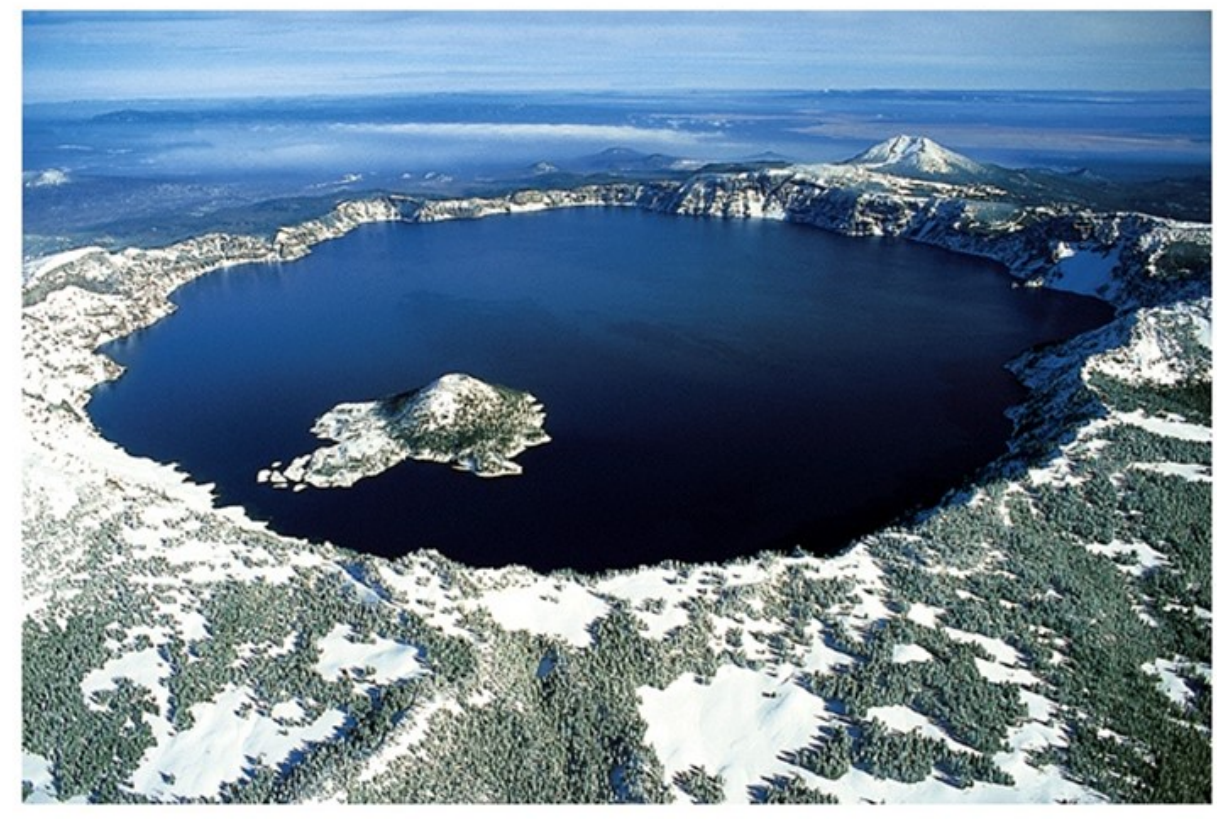




\section{Cyberseminar Presentation Notes}

1) Thank you for making the time today to join today's discussion- Today's call will focus on understanding the evidence for medication and lifestyle interventions to delay/prevent the onset of diabetes

a. Thank CMI for hosting, facilitating, and moderating this call

2) Lisa, Tracy and myself are from the EPC program. EPCs are federally funded entities that conduct large/complex systematic reviews. The KPRA EPC is based at CHR in Portland, OR and SoCal EPC is based at RAND.

a. We have no financial or intellectual conflicts to disclose.

3) Before we launch into the discussion of the evidence, I want to briefly give you some context as to the genesis of this call

a. AHRQ (our funder) is very interested in making the EPC reports of better utility to health care delivery systems and to this end has given us small funds to pilot collaboration between our EPCs and KP and has resulted specifically in this presentation- our aim is to see if an interactive format to link reviewers (and evidence reviews) to decision makers within KP helps with the translation of evidence

i. We are interested in what works and what doesn't, in particular, what information is needed for your decision making that is not in traditional systematic reviews conducted by EPCS

b. To keep this call more interactive, I will present a very high-level summary of the evidence and comments around implementation of lifestyle interventions. I will try to keep my prepared comments limited to $15 \mathrm{~min}$ and then hand over for others to talk about some interval evidence since the review and to moderate the discussion with the GDT and our invited guests.

c. We will circulate a short electronic survey after the meeting to get folks feedback on what was helpful or not, we welcome ANY input.

4) Early on we disseminated a list of recent EPC reports on CVD and DM related topics through $\mathrm{CMI}$, and we understood this review on screening for type $2 \mathrm{DM}$ by Selph et al. at the OHSU EPC was of interest given your current efforts around updating your screening for DM guidelines. As you may know this review was conducted in support of the recent USPSTF B recommendation to screen adults 40-70 who are overweight or obese for abnormal blood glucose.

5) This USPSTF recommendation made this positive recommendation to screen for abnormal glucose because intensive lifestyle interventions could prevent or delay the onset of diabetes, and not direct evidence that screening (vs no screening) reduced mortality, or that earlier or more intensive mgmt of CVD risk in persons with diabetes reduced mortality.

6) So, I've been asked to focus the presentation on 1 of the KQ's in the review- that is "do interventions for prediabetes (IFG or IGT) delay or prevent progression to type 2 DM?"

a. This question covered lifestyle interventions, medications, and multifactorial interventions

b. In the interest of time I will not cover other drug classes and combos or multifactorial interventions, as these were generally null findings 
7) As you listen to the evidence, ask how effective are the different lifestyle and medication interventions to prevent DM, and do the benefits outweigh the harms? We realize that often decisions to implement evidence require information not in reviews. So what information or evidence do you need that isn't covered in the review (or reviews you have looked at)?

8) Ok, now let's move onto the evidence. This is a snapshot of the evidence covered in the review. In the subsequent slides I'll go into a little more detail.

a. Most of the evidence is for lifestyle intervention, and that is what most of the presentation (and I suppose discussion) will focus on, and that despite a lot of clinical heterogeneity amongst the different interventions studied, it is clear that they can reduce the progression to $\mathrm{DM}$.

b. Metformin and other meds also have data, but they are less effective, or findings are not statistically significant (TZD). The estimates in this table are all from pooled analyses, except for the estimate for metformin which comes from DPP, which is still the best estimate for metformin. You can see that the reduction for metformin and alphaglucosidase inhibitors are smaller than those reductions observed for lifestyle interventions, and the effect for TZD in this review is not statistically significant.

c. Multifactorial interventions I will not cover in this presentation

9) First, I would like to show you the evidence for lifestyle interventions

10) I understand to date you have used a well conducted systematic review by Balk and colleagues that was done I support of the CDC's Community Guide ( $k=16$ studies that reported diabetes incidence as an outcome). So, we did a cross walk between the two reviews to see what new (if any) evidence this review ( $k=10$ trials that reported diabetes incidence as an outcome) included. Basically, there is some non-overlap, with the CDC review including more studies, the mismatch primarily due to differences in study publication dates, study design, and the TF review being a little more restrictive to studies more applicable to the US, and a couple that may have been missed in error

11) Here is a MA plot for the 10 trials included in the USPSTF review, the followup for these trials ranged from about 2-9 years, outlier of Da Qing study in China with 23y follow. Top study, also the largest study is the DPP trial, you can see from the pooled estimate (very bottom diamond) that the RR 0.57 or $43 \%$ reduction in diabetes incidence in the lifestyle compared to usual care group

12) Now I'm going to show you similarly formatted results for TZD and alpha glucosidase inhibitors, not going to discuss metformin as there was only one new small trial $(n=181)$ for metformin, so again the best data on the effectiveness of metformin to prevent DM comes from the DPP study

13) Here is a MA for the 3 trials on TZD included in the TF review, the review by Phung and colleagues (that you used) included 4 trials, one of which is not included in the TF review because it is in people with known CAD (not as applicable to a screening population). You can see the $\mathrm{f} / \mathrm{u}$ is relatively short, up to 3 years, and that the pooled results are not statistically significant and there is a large amount of heterogeneity.

a. Results from the Phung and colleagues review does show statistical significance, likely due to choice of statistical methods for pooling (D\&L) not because of their inclusion of PPAR trial 
b. Nonetheless both analyses are being driven by one large trial- DREAM trial (notes- good quality large international multi center RCT with factorial design $2 \times 2$ to examine ramapril and rosiglitazone, mean age 55 )

14) Here is a MA for the 4 trials included for AGI included in the TF review, the review by Phung and colleagues included 6 trials, 2 of which are not included in the TF review, I cannot tell why. These two trials were conducted in China and quite small $(n=75$ in both studies on the study medication). You can see the $\mathrm{f} / \mathrm{u}$ ranges from 3-8 years. And the pooled estimate is 0.65 or $35 \%$ reduction in diabetes (about the same as metformin and smaller than lifestyle interventions) compared to the placebo group.

a. The Phung and colleagues review found a similar point estimate, but their results were NOT statistically significant and likely due to the addition of two studies

15) One major limitation of all of the reviews is none of them explicitly look at harms

a. While lifestyle interventions don't have hypothesized harms associated with them, it is clear that there is a cost and opportunity cost associated with each of them

b. But an examination of harms for meds is necessary to determine their role in diabetes prevention

i. (notes JAMA $2007 \mathrm{MA}$ of harms rosiglitazone- with increase $\mathrm{MI}$ and $\mathrm{CHF}$ but not CVD mortality)

16) Now we are going to shift gears a bit and focus on some details that will inform implementation of the lifestyle interventions, as you listen to the last several minutes of the presentation, think about what should be offered, and in whom should it be offered to? That is how far do you want to extrapolate from the evidence (the studied interventions and populations).

17) I'm going to walk through 7 slides that talks about the details of the DPP trial. I chose DPP as this is the exemplar of the interventions studied. When appropriate I'll comment on considerations as they apply to the whole of evidence (that is all the studies included in the reviews) that addresses lifestyle interventions.

a. Comprehensive in that they focused on both diet and exercise, you can see the goals outlined on the slide, tailoring of messages and self-labeled as "flexible" and culturally sensitive

b. food and exercise logs

c. offered optional supervised exercise sessions (free)

d. true/consistent with whole of body of evidence, in that interventions focused on both diet and exercise, more than just didactic interventions, used audit and feedback (including self-monitoring), problem solving skills, and individualized care plans

18) important to note that the control group in DPP was not nothing, standard cared included written information with annual individual session

a. optional- in other studies use of wait list control or usual care- again usual care including 1-2 brief sessions and written (presumed not tailored) information

19) PCP was not involved in the intervention, only in terms of providing a referral, the program and recruitment coordinators were trained in $\mathrm{MI}$, the case manager had training in nutrition, exercise, and/or behavior modification

a. True/consistent with whole of body of evidence, in that interventions generally used trained individuals (i.e., nutritionists, health educators, nurses, psychologists, exercise 
professionals) but details of their training for the intervention delivered are most often not reported

20) DPP had in person visits- either individual or group, this is true for the whole of the body of evidence that examined the outcome of diabetes incidence

a. I'll speak to the evidence on virtual lifestyle interventions in a few moments

21) DPP was a very intensive regimented intervention 16 1-to-1 session over first 24 weeks then monthly individual or group sessions for maintenance, in the trial there was a mean $\sim 3 y$ maintenance, alluded to before persons also had access to BIW led exercise sessions

a. Across the effective lifestyle intervention studies, they were mostly high intensity- by that I mean 12-32 contacts, over 12 months up to 3 years (DPP the highest \# of contacts and longest duration), again, many provided or access to exercise equipment or classes

22) Many of the studies included do not offer materials to reproduce/implement the interventions studied, however DPP is one of the few that has publicly available materials (notes- as well as multiple implementation studies)

23) In addition to WHAT was done, I want to give a little more detail on WHO was studied, which may be helpful in understanding to whom the findings may be generalizable. These were volunteers through different (mostly academic) medical centers. They had IFG or IGT and generally overweight to obese

a. Study had a very rigorous process to foster adherence and retention

i. Quite an adherent group as evidence by $50 \%$ meeting wt loss goals and $3 / 4$ meeting exercise goals during the initial 6 months.

b. In general (across all the studies), these were adults without serious or acute medical conditions, mean age 51-67, mean BMI 29-34, many volunteer participants, and overall high recruitment and retention rates

24) The CDC review did include a few studies of virtual interventions- overall limited number of trials- and NONE of these trials reported on diabetes incidence as an outcome, and all have shorter term f/u 12-15 months

a. Most informative trial (see notes below by Ma and colleagues) evaluated a face to face vs DVD based intensive (12+ sessions). The virtual intervention did include online portal which included virtual support, generally high-income volunteers (may not have broad generalizability), results show, while effects were slightly larger for in person vs virtual, the virtual group did lose weight (about 35\% met 7\% DPP weight loss goal)

b. 2 other trials that were comparative effectiveness trials, meaning no true control group, evaluated virtual interventions vs enhanced programs with virtual support/interaction, and these two trials found that enhanced programs could result in weight loss at 12 months

25) A few summary remarks before turning this over to open up to discussion-

a. first that screening is important, arguably only important because we can prevent/delay the onset of diabetes and that intensive lifestyle interventions are more effective and less harmful than medications and likely have other beneficial effects not measured in the studies/systematic reviews

b. Using the Balk review as you have done is reasonable, it is more comprehensive than the USPSTF review, and although may have included studies less generalizable to the US, findings are $c / w$ than the USPSTF review 
c. Understanding what was studied and who was studied is important to make a considered decision about what to recommend/implement within Kaiser, that it is either a direct application of the evidence, or an explicit/considered extrapolation of the evidence (and I would advocate if it is an extrapolation of the evidence you have an opportunity and obligation to study/evaluate this)

d. Need to understand harms of medications to address their role in diabetes prevention (data presented and evaluated thus far is not adequate) 


\section{Appendix D. Cyberseminar Pre-Seminar Questions}

Please read through the first set of questions and try to answer these questions. These questions are for self-study only and meant to facilitate your participation in next week's presentation on the evidence for medication and lifestyle interventions to prevent or delay the onset of diabetes.

1. Why do we screen for diabetes? Does this improve the health and quality of life for our members?

2. With current KP screening guidance for diabetes, about how many members in your region have been identified to have "prediabetes" (impaired fasting glucose or impaired glucose tolerance)?

3. What proportion of members with prediabetes have been offered a program of intensive lifestyle counseling? How many members have participated in these types of programs?

4. What proportion of members with prediabetes are being treated with metformin?

5. Do clinicians in your region prescribe other medications in persons with prediabetes to delay or prevent the onset of diabetes?

6. What sort of lifestyle programs are offered in your region currently? What is the member out of pocket cost for these programs?

As you listen to the evidence next week think about what information you need or want to know to make evidence-based guidance on medication and lifestyle interventions to prevent or delay the onset of diabetes. What else do you want to know?

1. How effective are lifestyle interventions to delay or prevent the onset of diabetes?

a. What is more effective-lifestyle interventions or metformin, or both?

b. Are there other medications as effective as metformin?

c. What is the long-term effect of lifestyle changes and/or medications?

2. In whom are these interventions successful (i.e., who was studied and who benefited in the trials)?

3. Do the benefits of these interventions outweigh the harms (including opportunity cost and financial cost)?

a. What is the value of these interventions (i.e. cost versus benefit)?

4. What is the acceptability of effective interventions, (i.e., what do we know about our members' preferences about options to delay or prevent the onset of diabetes)?

After you listen to the presentation of the evidence next week, think about what interventions would you want to recommend to members to prevent or delay the onset of diabetes. How far do you want to extrapolate from the evidence?

1. What sort of lifestyle interventions should we be offering our members?

a. What is an effective "intensive" lifestyle intervention?

b. What is the feasibility and cost of "intensive" lifestyle interventions?

2. Who should be offered intensive lifestyle interventions?

3. When should metformin be offered?

a. Always? Only after a trial of lifestyle intervention (current KP recommendations are to retest persons with prediabetes within 6 months after completion of lifestyle intervention)? 